\title{
Structure-property effects on mechanical, friction and wear properties of electron modified PTFE filled EPDM composite
}

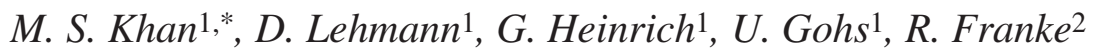 \\ ${ }^{1}$ Leibniz Institute of Polymer Research Dresden, Hohe Str. 6, 01069 Dresden, Germany \\ 2IMA Materialforschung und Anwendungstechnik GmbH Dresden, Wilhelmine-Reichard-Ring 4, 01109 Dresden, \\ Germany
}

Received 5 November 2008; accepted in revised form 9 December 2008

\begin{abstract}
Tribological properties of Ethylene-Propylene-Diene-rubber (EPDM) containing electron modified Polytetrafluoroethylene (PTFE) have been investiagted with the help of pin on disk tribometer without lubrication for a testing time of $2 \mathrm{hrs}$ in atmospheric conditions at a sliding speed and applied normal load of $0.05 \mathrm{~m} \cdot \mathrm{s}^{-1}$ and $F_{N}=1 \mathrm{~N}$, respectively. Radiation-induced chemical changes in electron modified PTFE powders were analyzed using Electron Spin Resonance (ESR) and Fourier Transform Infrared (FTIR) specroscopy to characterize the effects of compatibility and chemical coupling of modified PTFE powders with EPDM on mechanical, friction and wear properties. The composites showed different friction and wear behaviour due to unique morphology, dispersion behaviour and radiation functionalization of PTFE powders. In general, EPDM reinforced with electron modified PTFE powder demonstrated improvement both in mechanical and tribological properties. However, the enhanced compatibility of PTFE powder resulting from the specific chemical coupling of PTFE powder with EPDM has been found crucial for mechanical, friction and wear properties.
\end{abstract}

Keywords: mechanical properties, PTFE, EPDM, electron irradiation, friction

\section{Introduction}

Elastomers are special class of polymeric materials with exceptional elastic mechanical properties. The high elastic memory, high ultimate elongation and low elastic modulus in comparison to engineering thermoplastics recommend elastomers in wide range of special purpose applications. However, their significantly poor friction and wear properties restrict their use for tribological applications. This characteristic of rubber compound is not only required for tire performance but also in non-tire rubber goods where elastomeric component is in direct contact with a counter-surface. For this reason, a renewed interest can be noticed for rubber tribology because of the property requirement for rubber in engineering applications such as for dynamic and static sealing, automotive stripping and as gasket etc. [1].

This necessitates exploring on how the requested performance can be achieved by the formulation of rubber compounds. Different elastomeric compositions containing various kinds of friction-modifiers such as fibrous (glass, carbon, asbestos) and reinforcing fillers (molybendium disulfide, silica, graphite) have been investigated [2-5]. More recently Karger-Kocsis et al. have carried out detailed tribological investigations on rubbers containing novel reinforcing fillers such as organophilic nanoclay [6], carbon nanofibers and carbon nanotubes [7, 8]. Besides this, Polytetrafluoroethyl-

*Corresponding author, e-mail: khan@ipfdd.de

(C) BME-PT and GTE 
ene (PTFE) with its remarkably low friction coefficient has also gained interest for use in tribological applications [9-12]. In rubbers, PTFE was initially used as a reinforcing additive in Silicone and Fluorosilicone rubbers [13-15] and afterwards in Styrene-butadiene-rubber, Acrylonitrile-butadienerubber and Butyl rubber [16]. New PTFE-based rubber compounds and compounding procedures have been introduced in improving mechanical properties of both low-strength (ethylene propylene, silicone) and high-strength (nitrile) rubbers for O-rings, sealing and valves etc. [17]. However, PTFE especially in rubbers have not been achieved with any commercially significant success. This is mainly due to the intractability of PTFE in providing homogeneous formulation because of its poor wetting and dispersion characteristic. This problem results from the unique properties of PTFE, most probably its highly hydrophobic surface which resists wetting. There is indeed a strong motivation to investigate new techniques and procedures for the use of PTFE powder in rubber compound as solid lubricant for tribological applications.

More recently, chemically coupled PTFE-polyamide [18] and PTFE-rubber [19] compounds based on the modification of PTFE powder by high energy electrons has opened a new way in producing materials for tribological applications. Radiation functionalization produces PTFE micropowders containing persistent trapped-radicals radicals and functional groups on the surface of PTFE powder can be easily compounded into elastomers such as EPDM rubber. A detailed characterization related to the mechanical, friction and wear properties of PTFE-based EPDM compounds have been presented by the authors in $[20,21]$. In previous attempts the spectroscopic investigations revealed that during peroxide vulcanization the radiation- induced chemical changes in PTFE powder result in lower crosslinking efficiency and ultimately poor bulk properties of PTFE-EPDM composites $[22,23]$. The present study focuses on using electron irradiation for crosslinking the EPDM rubber containing PTFE powder to obtain elastomeric composites with comparable hardness and bulk properties. PTFE based composites were produced in a specific controlled manner so that the influence of morphology, dispersion and surface activity of different PTFE powders on mechanical and especially on friction and wear properties of elastomeric composites could be realized. These investigations are of significant importance regarding the application of PTFE powder in rubber compounds.

\section{Experimental}

\subsection{Materials and radiation modification of PTFE powder}

EPDM (Buna EP G 6850) with ethylidene norbornene (ENB) content $7.7 \mathrm{wt} \%$; ethylene content $51 \mathrm{wt} \%$; Mooney viscosity, ML (1+4) at $125^{\circ} \mathrm{C}$, 60 ; ash content $0.2 \mathrm{wt} \%$; specific gravity, $0.86 \mathrm{~g} \cdot \mathrm{cm}^{-3}$; was supplied from Lanxess Deutschland $\mathrm{GmbH}$, Leverkusen, Germany. The properties and producers of PTFE powders investigated in this study are listed in Table 1. PTFE powder L100X grade was modified with an absorbed dose of $500 \mathrm{kGy}$ at an average dose rate of about $10 \mathrm{kGy} / \mathrm{h}$ using electron accelerator (ELV-2) from Budker Institute of Nuclear Physics, Novosibirsk, Russia, installed at the Leibniz Institute of Polymer Research Dresden. The electron treatment was carried out in air and at room temperature. The transportation tray carrying PTFE powder passes to and fro under the beam exit-window (scanner) of electron accelerator. A $100 \mathrm{kGy}$ dose requires a pro-

Table 1. Properties of PTFE powders

\begin{tabular}{|l|c|c|c|}
\hline \multicolumn{1}{|c|}{ PTFE powder properties } & L100X* & MP1100** $^{* *}$ MP1200** $^{* *}$ \\
\hline Producers & Solvay Solexis, Italy & \multicolumn{2}{c|}{ DuPont, Wilmington USA } \\
\hline Polymerization process & emulsion & 500 & emulsion \\
\hline Irradiation dose $[\mathrm{kGy}]$ & 500 & 4 & suspension \\
\hline Primary particle size $[\mathrm{nm}]$ & $70-80$ & 15.13 & 3 \\
\hline Mean agglomerate size $[\mu \mathrm{m}]$ & 3.65 & 125.6 & 15.48 \\
\hline Carboxylic groups $(\mathrm{C}=\mathrm{O})$ & 44.13 & $7-10$ & 56.3 \\
\hline Radical concentration $[\%]^{* * *}$ & 100 & 26 & $1.5-3$ \\
\hline Specific surface area $\left[\mathrm{g} / \mathrm{m}^{2}\right]$ & & & \\
\hline
\end{tabular}

*irradiated in the institute

** commercially irradiated powders

****adical concentration normalized to L100X PTFE powder 
cessing time of $3 \mathrm{hrs}$ to perform 40 passes (each pass delivers $2.5 \mathrm{kGy}$ ). A shut down time of at least $8 \mathrm{hrs}$ was necessary after every successive $100 \mathrm{kGy}$ to allow sufficient diffusion of air in PTFE powder. For $500 \mathrm{kGy}$ dose, five steps each comprising of $100 \mathrm{kGy}$ dose were performed. The total time to achieve $500 \mathrm{kGy}$ dose was approx. $50 \mathrm{hrs,} \mathrm{includ-}$ ing $8 \mathrm{hrs}$ shutdown intervals. These treatment parameters have been chosen in order to avoid excess temperature rise which might favour deactivation of the radical formation as well as to influence the chemical structure of PTFE powder.

\subsection{Spectroscopic investigation of PTFE powder}

The relevant concentration of free radicals was determined with the help of MiniScope MS200 Electron Spin Resonance (ESR) instrument from Magnettech Limited, Berlin, Germany. Spin numbers for each PTFE grade were calculated prior to mixing with EPDM. Fourier Transform Infrared Spectrometer (FTIR) spectra were recorded on Vertex 80v (Bruker) FTIR spectrometer (4000$400 \mathrm{~cm}^{-1}$, resolution $=2 \mathrm{~cm}^{-1}, 32$ scans per measurement) from Bruker Optik $\mathrm{GmbH}$, Ettlingen, Germany in transmission mode on $10 \mu \mathrm{m}$ thin PTFE foils to observe the chemical changes induced in different PTFE powders. The concentration of carboxylic groups $(-\mathrm{COOH})$ was calculated using mathematical integration tool for the calculation of the area under the curve. The FTIR spectra have been normalized to Carbon-Fluorine (CF) upper vibration band at $2365 \mathrm{~cm}^{-1}$.

\subsection{Specimen preparation}

EPDM and $30 \mathrm{phr}$ (parts per hundred of rubber) PTFE powder were first pre-mixed in an internal mixer (PolyLab Haake Rheomix) from Thermo Electron $\mathrm{GmbH}$, Karlsruhe, Germany for 5 minutes at $100^{\circ} \mathrm{C}$ and at a rotor speed of $50 \mathrm{rpm}$. The material from internal mixer was placed in between nonsticking polyesters films for press molding at a temperature of $150^{\circ} \mathrm{C}$ and a pressure of $5 \mathrm{MPa}$ in an electrically heated press for 3 min to obtain rubber blocks of dimension $110 \mathrm{~mm} \times 110 \mathrm{~mm} \times 2 \mathrm{~mm}$. The molded samples of PTFE-EPDM were then crosslinked with energy rich electrons at $200 \mathrm{kGy}$ dose in atmospheric conditions and at room tem- perature of $25^{\circ} \mathrm{C}$. Crosslinking with $200 \mathrm{kGy}$ dose was accomplished in 5 passes with an absorbed dose of $40 \mathrm{kGy}$ per pass and at an average dose rate of about $25 \mathrm{kGy} / \mathrm{min}$. The processing time was 8 min with an electron energy and current of $1.5 \mathrm{MeV}$ and $4 \mathrm{~mA}$, respectively.

\subsection{Characterization}

Mechanical properties including tensile strength at break, relative elongation at break and modulus at 100\% (M100) and 200\% (M200) were determined according to ISO 527 at a cross-head speed of $200 \mathrm{~mm} / \mathrm{min}$ using tensile testing machine from Zwick GmbH, Ulm Germany. Hardness values were measured according to DIN 53505, using a Shore (A) Durometer from Heinrich BAREISS $\mathrm{GmbH}$, Oberdischingen, Germany. Indentations were made at several points for each specimen for measurements of average hardness values.

The frequency-temperature dependent viscoelastic mechanical property of the compounds, the loss factor or tan delta $\left(E^{\prime \prime} / E^{\prime}\right)$ was measured with the help of a dynamic mechanical analyzer, EPLEXOR ${ }^{\circledR}$ 150 N (Gabo Qualimeter Testanlagen $\mathrm{GmbH}$, Ahlden, Germany) using a $2 \mathrm{~mm}$ thick rectangular rubber block having an area of $15 \mathrm{~mm} \times 8 \mathrm{~mm}$. The temperature scans were run from $-100^{\circ} \mathrm{C}$ to $150^{\circ} \mathrm{C}$ at a heating rate of $4 \mathrm{~K} \cdot \mathrm{min}^{-1}$. The measurements were done in tension mode at a strain and frequency of $0.5 \%$ and $10 \mathrm{~Hz}$, respectively.

Micro-structure morphology and dispersion analysis of PTFE powder were determined with the help of LEO 435 scanning electron microscope (SEM acceleration voltage $20 \mathrm{kV}$ ) from LEO Electron Microscopy Ltd, Cambridge, England. Cryogenically fractured composites were used for the dispersion analysis of PTFE powder in EPDM. SEM was also used to assess the wear mechanisms involved rubber composites.

\subsection{Friction and wear testing}

A pin on disk tribometer according to ASTM G 99-2005 (ISC 200 from Implant Sciences, Wakefield, USA) was used as shown in Figure 1. Hardened carbon steel balls (type $100 \mathrm{KU} 15 \mathrm{KL} 3$, Wälzlagertechnik Dresden, Germany) made of the steel 100Cr6 (German standard 100Cr6, near AISI L3 steel) with a diameter of $15 \mathrm{~mm}$ served as coun- 

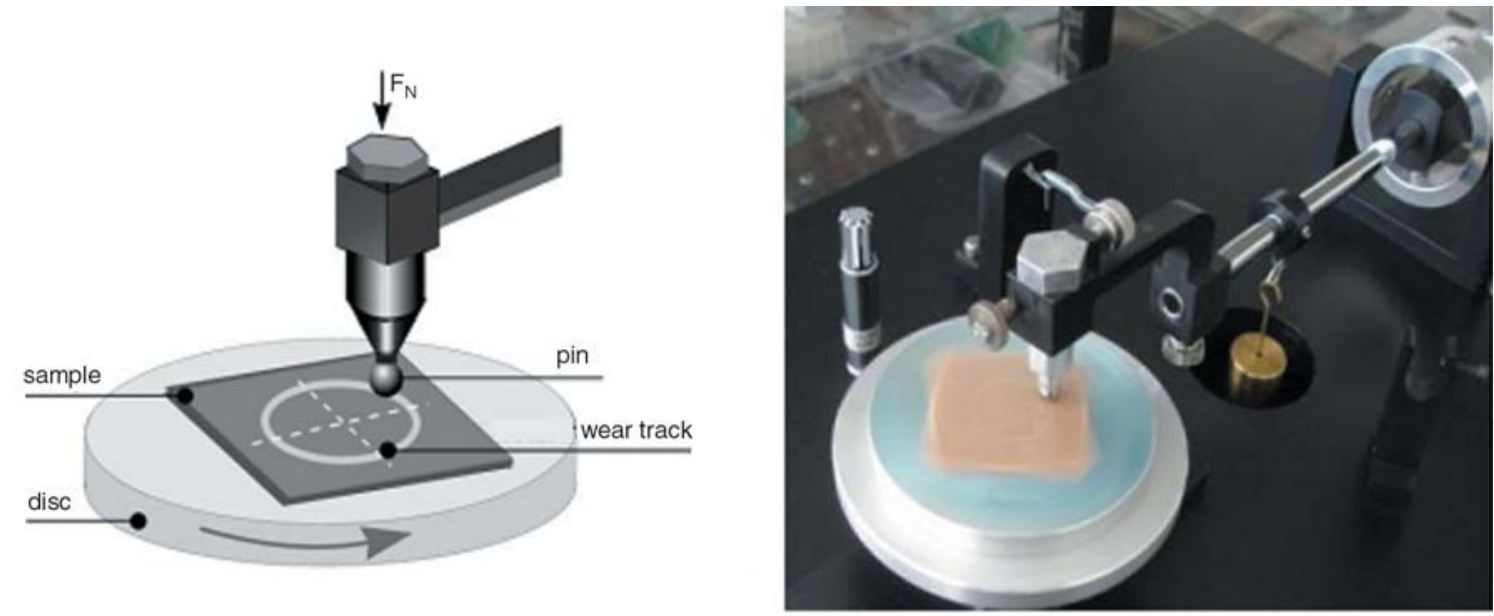

Figure 1. Schematic (left) of the pin-on-disk tribometer (right) illustrating the testing set-up for the friction and wear characterization of rubber sample (mounted on disk) against a counter-surface (pin/steel ball)

terpart. The surface of the steel balls were grinded with an arithmetic average roughness of $R_{a}=$ $0.47 \mu \mathrm{m}$. The compound specimens were manufactured as square plates with dimensions $40 \mathrm{~mm} \times$ $40 \mathrm{~mm}$, thickness $h=2 \mathrm{~mm}$ and bonded on the steel disc using double-sided tesafilm ${ }^{\circledR}$. A sliding speed of $0.05 \mathrm{~m} \cdot \mathrm{s}^{-1}$ was applied. The diameter of the circle rotation was $10 \mathrm{~mm}$ in each case. The tribological investigations were performed at a constant load of $F_{N}=1 \mathrm{~N}$ over a testing time of $t_{B}=$ $2 \mathrm{~h}$. The tests were carried out at a temperature of $22.9^{\circ} \mathrm{C}$ and a relative humidity of $31 \%$. Profilometry of the wear track was conducted with profilometer (Perthometer CONCEPT 6.2, Mahr, Göttingen, Germany) at four different locations. In each case the point was shifted around $90^{\circ}$ angle. For determination of the specific wear rate $(k)$, the cross-sectional area of wear track was calculated by approximating the shape of the wear scar with a segment of circle. Specific wear rate was calculated as per Equation (1):

$$
k=\frac{W_{V}\left[\mathrm{~mm}^{3}\right]}{F_{N} \cdot s[\mathrm{~N} \cdot \mathrm{m}]}
$$

where $W_{V}$ is the volume of the removed material, $F_{N}$ is the normal load and $s$ is the sliding distance. The friction coefficient $(\mu)$ was determined directly by measuring the tangential force with a strain gauge load cell and recorded continuously with a sampling rate of $100 \mathrm{~Hz}$. In case of stick slip effect, the experimental data strongly fluctuated and therefore for qualitative analysis of the friction behaviour of different composites the average values of friction coefficients are reported. The average friction coefficient was calculated as mean of maximum and minimum friction coefficient values, i.e. $\mu=\left(\mu_{\max }-\mu_{\min }\right) / 2$. For all series the mass wear loss of the counterpart ball was lower than the detection limit of the weighing balance (RC 1 from Satorius AG, Göttingen, Germany) which works with an accuracy of $0.1 \mathrm{mg}$.

\section{Results and discussion}

\subsection{Optimization of crosslinking irradiation dose}

In order to investigate the effect of morphology, dispersion and chemical coupling, the composites should have hardness higher than the critical value of 58 Shore (A) as determined in [22, 23]. Peroxide vulcanization of PTFE-EPDM composites containing electron modified PTFE powder is strongly influenced by the irradiation-induced changes in PTFE powder. Hardness of PTFE-EPDM compounds vary according to absorbed dose of PTFE powder. For this reason, EPDM has been vulcanized using electron irradiation in order to suppress this undesired effect on composite's hardness. The dose for electron crosslinking was determined relative to the required hardness values of PTFEEPDM compounds. This was achieved by monitoring the influence of crosslinking dose on hardness of composites. Figure 2 shows the influence of absorbed dose on hardness of EPDM rubber and PTFE-EPDM composites. It can be seen that the optimum dose for crosslinking of EPDM rubber amounts to about 80 to $120 \mathrm{kGy}$. Above $120 \mathrm{kGy}$, 


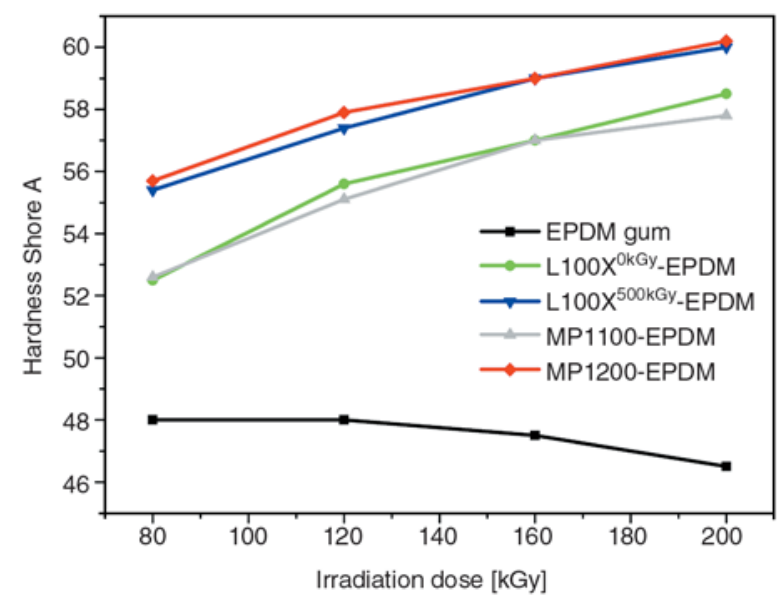

Figure 2. Comparison of hardness values of EPDM gum and PTFE-EPDM composites as a function of crosslinking irradiation dose

hardness decreases due to chain scission of EPDM. However, in the presence of PTFE powder, hardness of EPDM-PTFE composites increases as expected. L100X ${ }^{500 k G}$-EPDM and MP1200-EPDM show highest while L100X ${ }^{0 \mathrm{kGy}-E P D M}$ and MP1100-EPDM show lowest hardness. This behaviour is in contradiction to that observed in peroxide induced vulcanization of L100X ${ }^{500 k G y}$-EPDM composite $[22,23]$. It suggests that the variation in hardness of different composites at any specific absorbed dose results from differences in the chemical coupling mechanism of PTFE powders. This can be clearly seen in the different hardness values of L100X ${ }^{0 \mathrm{kGy}-E P D M}$ and L100X ${ }^{500 \mathrm{kGy}-E P D M}$ composites. However, at an optimum crosslinking dose of $200 \mathrm{kGy}$ all of the PTFE-EPDM compos-

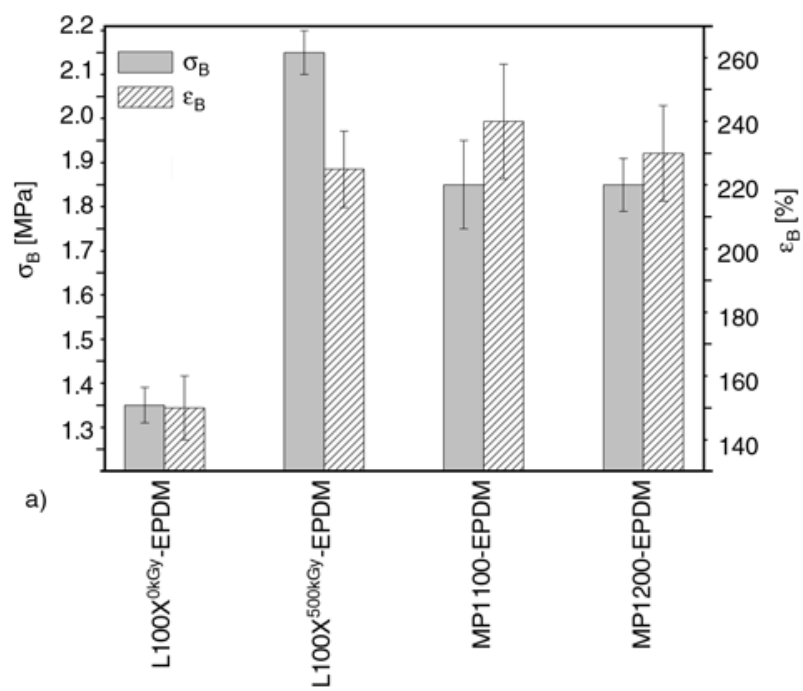

ites attained the required minimum hardness value of 58 Shore (A).

\subsection{Mechanical and dynamic mechanical properties}

The effects of PTFE powders on mechanical properties of PTFE-EPDM composites are shown in Figure 3. As expected modified PTFE-EPDM composites compared to non-modified (L100X $\mathrm{X}^{\mathrm{k} G \mathrm{G}-\mathrm{EPDM})}$ shows enhanced properties. There is no significant variation in tensile strength and elongation at break values of all modified PTFE-EPDM composites. However, L100X ${ }^{500 k G y-E P D M ~ s h o w s ~ t h e ~ h i g h e s t ~}$ M100 and M200 followed by MP1200-EPDM and

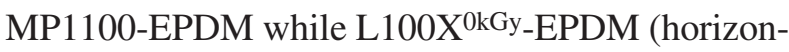
tal broken line) shows the lowest. M200 was not achieved by L100X ${ }^{0 k G y}$-EPDM. This reinforcement effect in case of L100X ${ }^{500 k G y}$-EPDM is due chemical coupling of PTFE powder with EPDM. The effect of reinforcement can also be seen in the tan delta curves of composites shown in Figure 4. As can be seen the glass transition temperature $\left(T_{g}\right)$ is only slightly influenced by addition of different PTFE powders to EPDM. The peak-height increases from MP1200-EPDM to L100X ${ }^{500 k G y-E P D M ~ a n d ~}$ reaches the maximum value for $\mathrm{L} 100 \mathrm{X}^{0 \mathrm{kGy}}-\mathrm{EPDM}$ and MP1100-EPDM. L100X ${ }^{0 k G y}$-EPDM, MP1100EPDM and MP1200-EPDM show similar $T_{g}$ of about $-38^{\circ} \mathrm{C}$ whereas $\mathrm{L} 100 \mathrm{X}^{500 \mathrm{kGy}}-\mathrm{EPDM}$ has a higher $T_{g}$ value of about $-35^{\circ} \mathrm{C}$. This shift in $T_{g}$ to higher temperature is due to the restricted mobility of the polymer chains. Figure 4 also shows the mag-

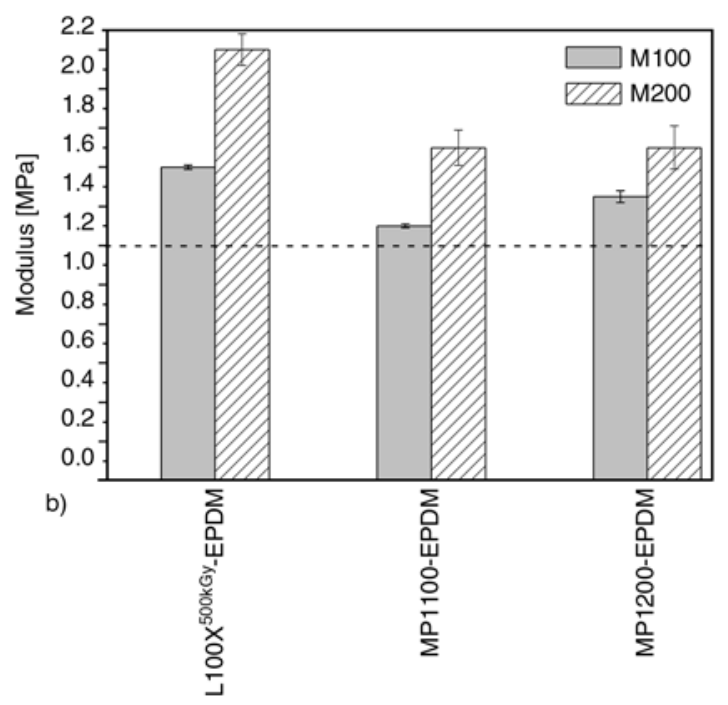

Figure 3. Tensile strength at break $\left(\sigma_{B}\right)$ and elongation at break $\left(\varepsilon_{B}\right)$ are shown in figure (a) while modulus, M100 and M200 are shown in figure (b). The horizontal broken lines indicate M100 of L100X ${ }^{0 \mathrm{kGy}}$-EPDM. 


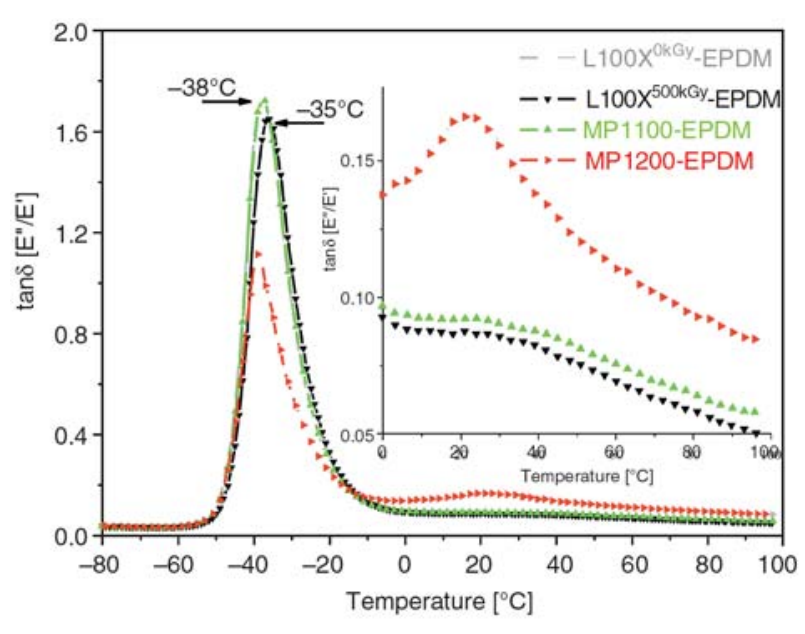

Figure 4. Tan delta behaviour of PTFE filled EPDM composites as a function of temperature

nified tan delta curves of the compounds in the temperature range of friction and wear testing where L100X ${ }^{500 k G y-E P D M}$ shows the lowest tan delta while L100X ${ }^{0 \mathrm{kGy}}$-EPDM and MP1100-EPDM shows similar behaviour at slightly higher level. The upturn in tan delta behavior of MP1200-EPDM could be due to the relaxation processes associated with the radiation-induced effects on crystallites structure of PTFE powder.

\subsection{Compatibility and dispersion}

Table 1 shows the relative concentration of $\mathrm{C}=\mathrm{O}$ groups determined in the region $1840-1740 \mathrm{~cm}^{-1}$. It can be observed that $\mathrm{C}=\mathrm{O}$ concentration varies in different PTFE powders. L100X500kGy PTFE powder shows the highest concentration of $\mathrm{C}=\mathrm{O}$ groups while both MP1100 and MP1200 being three times less than L100X ${ }^{500 k G y}$ PTFE powder have almost similar concentration of $\mathrm{C}=\mathrm{O}$ groups. Higher concentration of $\mathrm{C}=\mathrm{O}$ groups in case of $\mathrm{L} 100 \mathrm{X}^{500 \mathrm{kG} y}$ PTFE powder suggests significantly lower contact angle or higher wettability. Lower contact angle corresponds to higher surface energy and enhanced interaction with polar compounds such as water. However, the enhanced compatibility of irradiated PTFE and EPDM cannot be explained by the presence of these functional groups since EPDM being a non-polar compound does not interact via polar or $\mathrm{H}$-bonding forces. The other influencing factor is the relative concentration of persistent free radicals trapped in the crystalline structure at the surface of modified PTFE powders as shown in Table 1. The trapped radicals affect the properties through radi- cal coupling with the olefinic unsaturation diene in rubber compound. The overall (bulk and surface) radical concentration of PTFE powders normalized to L100X ${ }^{500 k G y}$ PTFE powder $(100 \%)$ suggest that MP1100 has the highest (125.6\%) while MP1200 (56.3\%) indicates the lowest radical concentration. However, the degree of chemical coupling might also depend on the amount of radicals available on the surface of PTFE powders for chemical coupling with EPDM rather than the bulk concentration. In such case the surface to available radical concentration is of significant importance.

Figure 5 shows the scanning micrographs of PTFEEPDM composites. It can be seen that L100X ${ }^{0 \mathrm{kGy}}$ EPDM demonstrates poor compatibility and dispersion. It shows bigger agglomerates with poor dispersion behaviour in EPDM. This is due to the highly inert and hydrophobic surface of PTFE powder which lacks chemical compatibility with EPDM matrix. For this reason PTFE powder is modified with electron irradiation in order to enhance simultaneously its poor compatibility and dispersion characteristic. As observed in Figure 5, L100X ${ }^{500 k G y}$ PTFE powder in comparison to L100X ${ }^{0 \mathrm{kGy}}$ PTFE powder shows improved dispersion and compatibility. The enhanced compatibility due to the chemical coupling by radical mechanism helps in de-agglomeration and dispersion of PTFE agglomerates during the reactive processing. Grafted EPDM chains on the surface of PTFE particles interact with the EPDM matrix and as such extensive shearing and de-agglomeration provides new active sites for chemical coupling with the olefinic unsaturated diene of EPDM. This helps in reinforcement and simultaneously improves the properties of L100X ${ }^{500 k G y-E P D M}$ as shown in Figures 3 and 4. MP1100 shows the most excellent dispersion amongst the PTFE powders investigated. This is mainly due to the ability of this special grade of PTFE powder to de-agglomerate to its primary particle size of $0.2 \mu \mathrm{m}$. Both MP1100 and L100X ${ }^{500 k G y}$ PTFE powders are embedded firmly in EPDM matrix. However, L100X grade is difficult to disperse uniformly compared to MP1100 even though both are produced by emulsion polymerization. On the other hand MP1200 PTFE powder having solid morphology is difficult to deagglomerate even under high shearing. The agglomerates are pulled out of EPDM on application of stress. This clearly indicates the lower or 

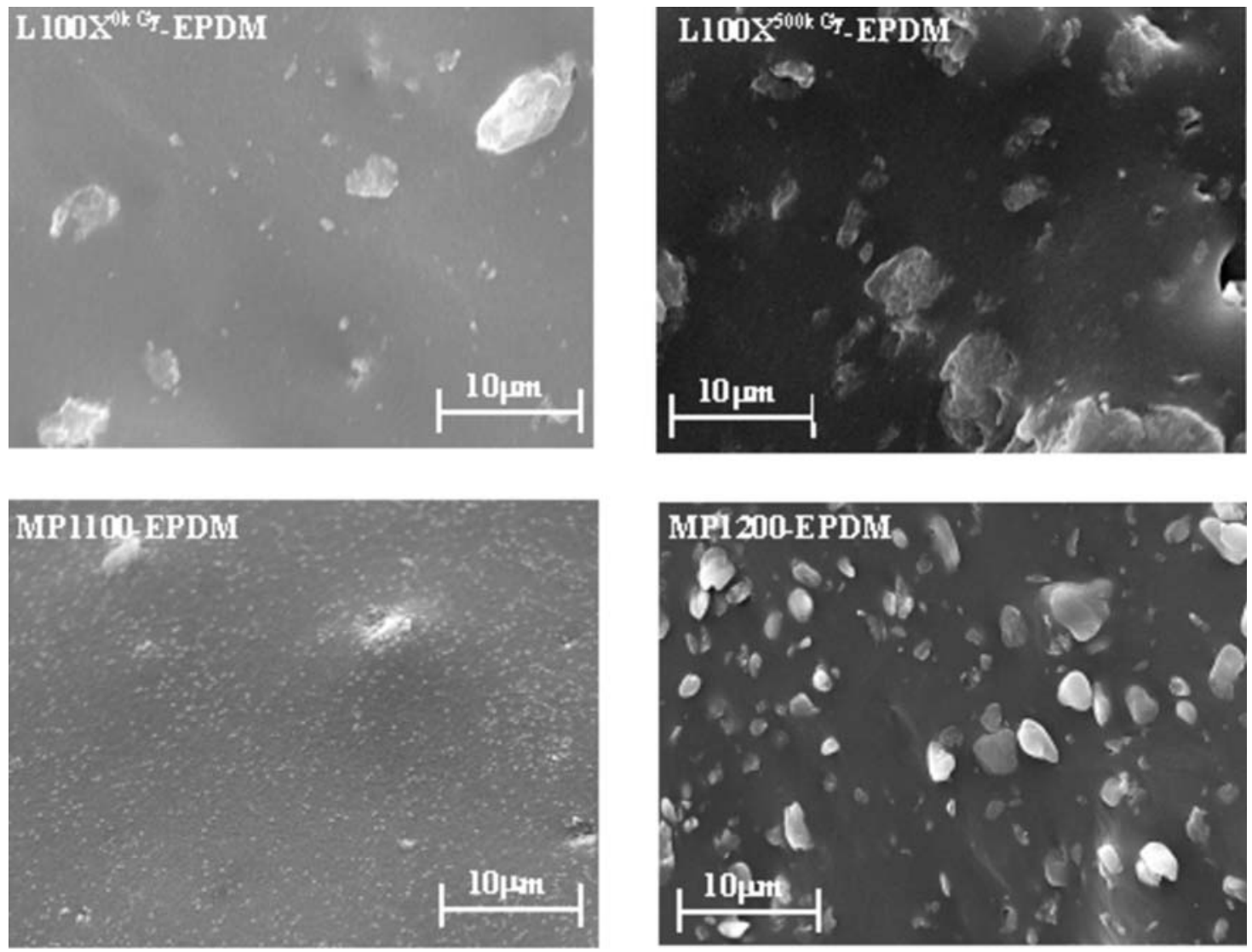

Figure 5. Scanning micrographs of the cryogenically fractured surfaces showing PTFE morphology and dispersion in EPDM

insufficient degree of compatibility of the bigger MP1200 agglomerates. The surface of EPDM indicates the presence of many PTFE particles. This clearly shows the difficulty in obtaining uniform dispersion of MP1200 in EPDM matrix.

\subsection{Friction properties}

Figure 6 shows the friction behaviour of PTFEEPDM composites sliding against a hard spherical ball. The friction curves demonstrate that the friction coefficients of all vulcanizates decreases during the course of testing. The friction coefficient values decreases from initial to the final fiction values with in a range of 4 to $100 \%$. As can be seen the elastomeric composites show different behaviour both at the beginning and during the course of testing time. MP1100-EPDM shows the highest friction in comparison to the other composites. Moreover, a sudden decrease in initial friction coefficient is observed for all compounds except for MP1100-EPDM. After a steady state is achieved, friction coefficient of MP1200-EPDM and L100X ${ }^{0 k G y}$-EPDM remains almost constant up to the end of measurement. On the contrary, MP1100EPDM shows a gradual decrease in friction coefficient. This behaviour can be approximated by a linear function having a negative slope.

Similarly, L100X ${ }^{500 k G y}-E P D M$ shows the same behaviour after steady state condition has been achieved. However, the slope of the friction curve is less than MP1100-EPDM. This clearly shows the

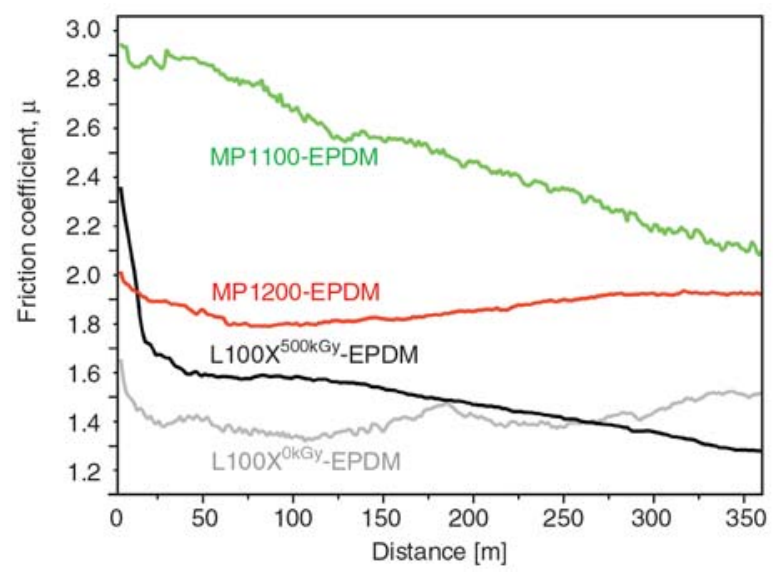

Figure 6. Comparison of the friction behaviour of different PTFE-EPDM composites as a function of sliding distance 
influence of PTFE powders on friction behaviour of EPDM matrix. The higher friction values of MP1100-EPDM could be due to the direct interaction of the counter-body with EPDM. As is obvious in Figure 5, the surface of MP1100-EPDM is the smoothest of all the investigated composites due to its enhanced compatibility and excellent dispersion. There is almost no indication of PTFE particles on the surface. Only a few agglomerates are visible. Thus there is a rare possibility for MP1100 PTFE powders to form a transfer film during sliding contact against the counter-body. This results in a significantly higher friction coefficient throughout the testing time. On the other hand, all other composites show significantly lower friction values. This is due to the presence of PTFE agglomerates on the surface which allows a direct interaction with the counter-surface once EPDM layer is removed. This can be clearly seen in the sudden decrease in friction coefficients as shown in Figure 6. Moreover, a further decrease in case of L100X ${ }^{500 k G y}$-EPDM compared to $\mathrm{L} 100 \mathrm{X}^{0 \mathrm{kGy}}$ EPDM and MP1200-EPDM is observed. This is due to the interaction of the embedded PTFE agglomerates in wear track of L100X ${ }^{500 k G y}$-EPDM with counter-body. This facilitates in easy sliding of the counter-body against a wear track covered with PTFE particles.

\subsection{Wear properties}

Figure 7 shows the specific wear rates $(k)$ of PTFE filled EPDM composites. Specific wear rates respond in accordance with the friction behaviour. The specific wear rate changes with in a range of $40 \%$ (L100X ${ }^{500 \mathrm{kGy}}$ ) to $400 \%$ (MP1100-EPDM). MP1100-EPDM with its significantly high friction coefficient suffered from higher wear rate. Similarly, L100X ${ }^{0 k G y-E P D M}$ and MP1200-EPDM having low friction coefficients show comparatively lower wear rates.

Figure 8 shows scanning micrographs of the wear scars of composites after repeated sliding with the counter-body. It can be seen that different wear mechanisms have occurred in the composites. In case of L100X ${ }^{0 \mathrm{kGy}}-\mathrm{EPDM}$, wear behaviour is characterized by the detachment of PTFE agglomerates from EPDM due to its significantly poor compatibility with EPDM. At higher magnification it also

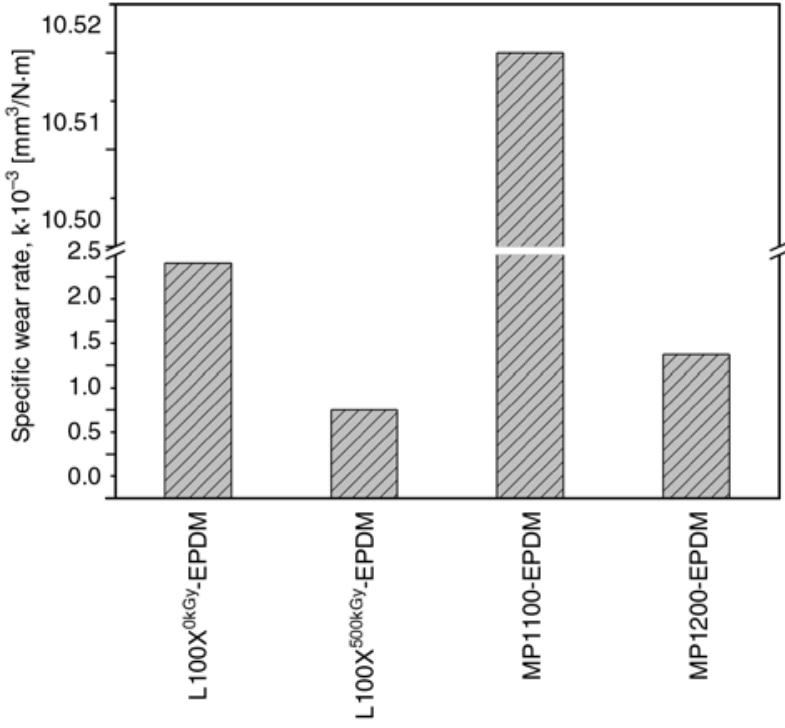

Figure 7. Comparison of the specific wear rates $(k)$ of PTFE filled EPDM composites during friction testing

shows the presence of flattened agglomerates. This indicates that PTFE powder may have been transferred to the counter-surface. However, in case of L100X ${ }^{500 k G y-E P D M, ~ t h e ~ w e a r ~ t r a c k ~ i s ~ s m o o t h . ~ I t ~}$ shows the presence of significant amount of embedded PTFE agglomerates that have been flattened or abraded by repeated sliding of the counterbody. This is in accordance with the friction mechanism described before. The interaction of counter-body with PTFE agglomerates results in both the lowest wear rate and friction coefficient. In contradiction, MP1100-EPDM shows a rough wear track due to the detachment of significantly large lumps from the top of the surface. The wear mechanism is similar to the de-lamination type wear that has occurred in the deep regions of EPDM. At higher magnification one can observe that no PTFE agglomerates are visible for contact with counterbody. Thus almost no PTFE has been transferred to the counter-surface. MP1200-EPDM suffered from wear mechanism similar to MP1100-EPDM and L100X ${ }^{0 k G y}$-EPDM. A comparatively smaller lumps compared to MP1100-EPDM have been removed from the top of the surface. On the other hand, MP1200 being bigger and less compatible agglomerates have been removed from EPDM similar to L100X ${ }^{0 \mathrm{kGy}}$-EPDM. One can observe the presence of these detached PTFE agglomerates on the wear track surface. 

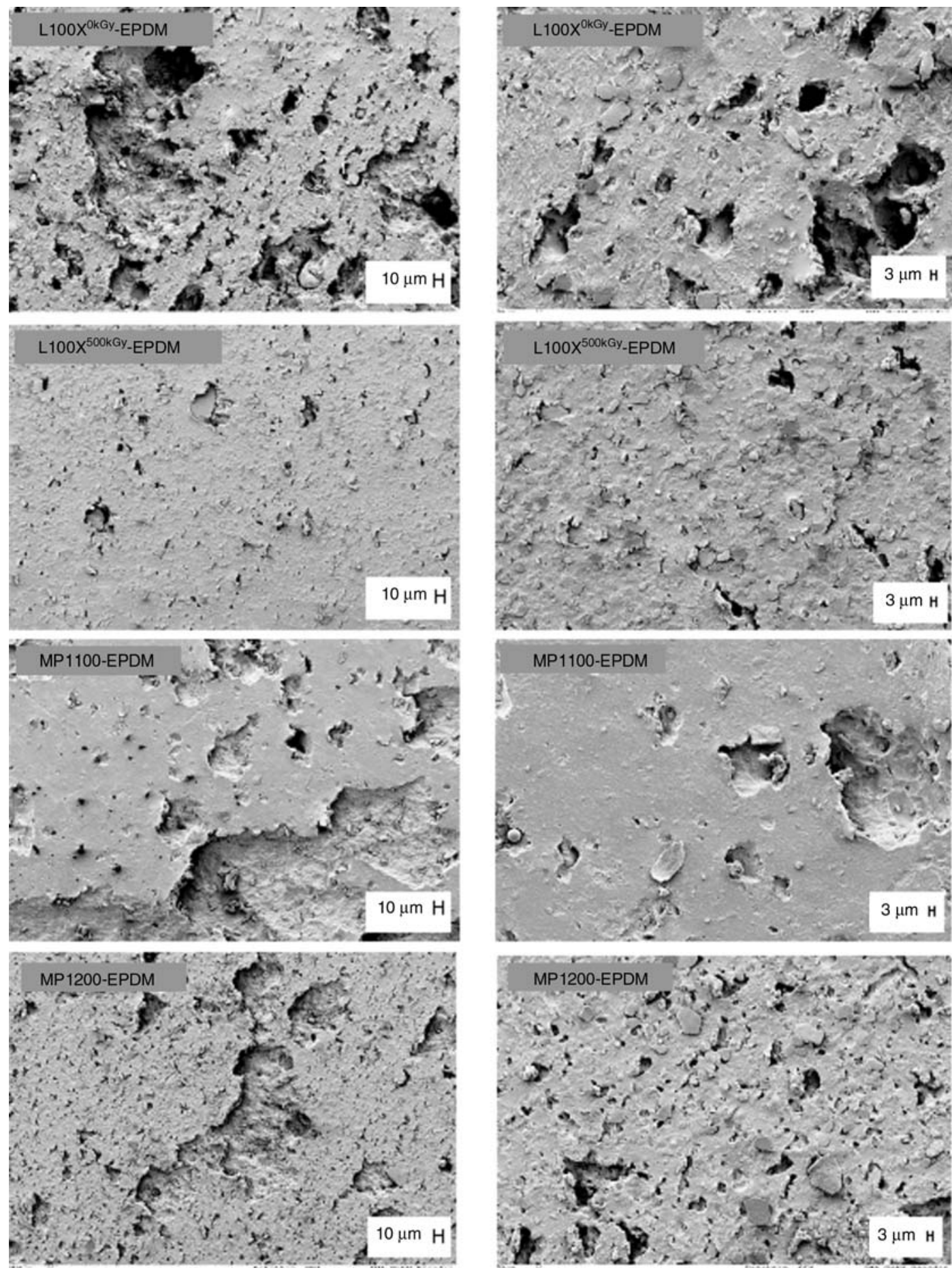

Figure 8. Scanning micrographs of wear track (contact area) showing the wear mechanisms involved in different PTFEEPDM composites

\section{Conclusions}

The specific interaction of different PTFE powders with EPDM as well as with the counter-surface (steel-ball) controls mechanical as well as friction and wear properties of PTFE filled EPDM vulcanizates. L100X ${ }^{500 k G y-E P D M}$ shows improved mechanical, dynamic mechanical and tribological properties due to enhanced chemical compatibility with EPDM. The significant improvement in fric- tion and wear properties results from the embedment of L100X ${ }^{500 k G y}$ PTFE agglomerates in EPDM matrix. This enable the counter-surface in easy sliding against a wear track covered with embedded PTFE particles. Friction and wear properties are strongly influenced by PTFE dispersion, PTFE transfer film formation and the corresponding chemical interaction between PTFE powder and EPDM matrix. MP1100-EPDM shows signifi- 
cantly poor friction and wear properties but maintains excellent dispersion while MP1200-EPDM and L100X0kGy-EPDM with comparatively improved friction and wear properties are characterized with poor dispersion and chemical compatibility of PTFE powder with EPDM. The described approach opens the route for potential use of electron modified PTFE powder in a variety of rubber compounds for tribological applications. However, a direct evidence of the existence, nature and the influence of chemical coupling between electron modified PTFE powder and EPDM rubber is necessary in order to design materials for tribological applications based on PTFE in technical rubber formulations.

\section{Acknowledgements}

The authors thank Solvay Solexis S.p.A. Italy and DuPont, Wilmington, DE, USA for the free of charge supply of PTFE powders.

\section{References}

[1] Bock E.: Sealing systems in a combustion engine (in German). Gummi Fasern Kunststoffe, 3, 180-187 (2004).

[2] Bjerk R., Brandon W., Engelkin F., Jero J.: Fluoroelastomer-based composite material. U.S. Patent 3898361, USA (1975).

[3] Scher I. H., Ungar S. I.: Abrasion-resistant laminate. U.S. Patent 4400423, USA (1983).

[4] Bjerk R., Brandon W., Engelkin F., Jero J.: Fluoroelastomer-polyacrylate based friction material. U.S. Patent 4045402, USA (1977).

[5] Defrank M. P.: Epoxy-rubber based friction material. U.S. Patent 4131590, USA (1978).

[6] Gatos K. G., Kameo K., Karger-Kocsis J.: On the friction and sliding wear of rubber/layered silicate nanocomposites. Express Polymer Letters, 1, 27-31 (2007).

DOI: 10.3144/expresspolymlett.2007.6

[7] Karger-Kocsis J., Felhôs D., Thomann R.: Tribological behavior of a carbon nanofiber modified santoprenes thermoplastic elastomer under dry sliding and fretting conditions against steel. Journal of Applied Polymer Science, 108, 724-730 (2008).

DOI: 10.1002/app.27429

[8] Felhôs D., Karger-Kocsis J., Xu D.: Tribological testing of peroxide cured HNBR with different MWCNT and silica content under dry sliding and rolling conditions against steel. Journal of Applied Polymer Science, 108, 2840-2851 (2008).

DOI: 10.1002/app.27624
[9] Tanaka K., Kawakami S.: Effect of various fillers on the friction and wear of PTFE-based composites. Wear, 79, 221-234 (1982). DOI: $10.1016 / 0043-1648(82) 90170-3$

[10] Bahadur S., Tabor D.: The wear of filled polytetrafluoroethylene. Wear, 98, 1-13 (1984). DOI: $10.1016 / 0043-1648(84) 90213-8$

[11] Friedrich K., Lu Z., Hager A. M.: Recent advances in polymer composites' tribology. Wear, 190, 139-144 (1995).

DOI: 10.1016/0043-1648(96)80012-3

[12] Burris D. L., Boesl B., Bourne G. R., Sawyer W. G.: Polymeric nanocomposites for tribological applications. Macromolecular Materials Engineering, 292, 387-402 (2007).

DOI: $10.1002 /$ mame. 200600416

[13] Crandell W. H.: Evaluation of silicon rubber modified with teflon. Rubber World, 133, 236-240 (1955).

[14] Kaufman M. H., Gonzales J.: Reinforcement of fluoroelastomers with halopolymers. Rubber Chemistry and Technology, 41, 527-532 (1968).

[15] Magner L. M., Punderson J. O.: Blends of fluorinated polymers. U.S. Patent 3484503, USA(1969).

[16] Kaufman M. H.: Hydrocarbon polymers. U.S. Patent 3940455, USA (1976).

[17] Stewart C. W.: Elastomeric compositions containing treated PTFE. U.S. Patent 4507439, USA (1985).

[18] Franke R., Lehmann D., Kunze K.: Tribological behaviour of new chemically bonded PTFE polyamide compounds. Wear, 262, 242-252 (2007).

DOI: 10.1016/j.wear.2006.05.001

[19] Haberstroh E., Linhart C., Epping K., Schmitz T.: Improving the tribological properties of elastomers by PTFE powder (in German). Kautschuk Gummi Kunststoffe, 59, 447-453 (2006).

[20] Khan M. S., Lehmann D., Heinrich G.: Properties of the EPDM with modified PTFE Nanopowder. Kautschuk Gummi Kunststoffe, 60, 226-234 (2007).

[21] Khan M. S., Lehmann D., Heinrich G.: Modification of PTFE nanopowder by controlled electron beam irradiation: A useful approach for the development of PTFE coupled EPDM compounds. Express Polymer Letters, 2, 284-293 (2008). DOI: $10.3144 /$ expresspolymlett.2008.34

[22] Khan M. S., Lehmann D., Heinrich G., Franke R.: Tribological studies of peroxide-cured EPDM rubber filled with electron beam irradiated PTFE powder. Wear, 266, 200-207 (2009). DOI: $10.1016 /$ j.wear.2008.06.014

[23] Khan M. S., Franke R., Gohs U., Lehmann D., Heinrich G.: Friction and wear behaviour of electron beam modified PTFE filled EPDM compounds. Wear, 266, 175-183 (2009). DOI: $\underline{10.1016 / j . w e a r .2008 .06 .012}$ 